\title{
Thalamic-Evoked Synaptic Interactions in Barrel Cortex Revealed by Optical Imaging
}

\author{
Nora Laaris, Greg C. Carlson, and Asaf Keller \\ Department of Anatomy and Neurobiology and Program in Neuroscience, University of Maryland School of Medicine, \\ Baltimore, Maryland 21201
}

We used optical imaging of voltage-sensitive dye signals to study the spatiotemporal spread of activity in the mouse barrel cortex, evoked by stimulation of thalamocortical afferents in an in vitro slice preparation. Stimulation of the thalamus, at low current intensity, results in activity largely restricted to a single barrel, and to the border between layers $\mathrm{Vb}$ and $\mathrm{VI}$. Low concentrations of the $\mathrm{GABA}_{A}$ receptor antagonist bicuculline increase the amplitude of the optical signals, without affecting their spatiotemporal propagation. Higher concentrations of bicuculline result in paroxysmal activity, which propagates via intracolumnar and intercolumnar excitatory pathways. Enhancing the activity of NMDA receptors, by removing $\mathrm{Mg}^{2+}$ from the extracellular solution, dramatically alters the spatiotemporal pattern of excitation: activity spreads to supragranular and infragranular layers and adjacent barrel columns. This enhanced propagation is suppressed by the NMDA receptor antagonist AP5. A similar enhancement of activity propagation can be produced by stimulating the thalamus with a short, high-frequency pulse train. Application of AP5 suppresses the frequency-dependent spread of activity. These findings indicate that the spatiotemporal spread of activity in the barrel cortex is altered by varying the temporal patterns of thalamic inputs, via an NMDA receptor-mediated mechanism, and suggest that a similar process occurs during repetitive whisking activity.

Key words: somatosensory cortex; voltage-sensitive dyes; glutamate; NMDA; GABA; epilepsy; temporal coding; mouse
Processing of sensory information in the cerebral cortex can be described as a hierarchical process, in which inputs from "specific" thalamic nuclei are integrated by their postsynaptic cortical targets, which, in turn, provide inputs to neurons in other layers of the same functional column and subsequently to adjacent columns (Gilbert, 1992; Keller, 1995; Rauschecker et al., 1997). Although this hierarchical scheme is oversimplified in that it omits factors such as parallel processing and feedback interactions, it is thought to faithfully represent at least the initial stages of cortical sensory processing (Stone et al., 1979; Felleman and Van Essen, 1991; Iwamura, 1993).

To understand the mechanisms underlying cortical sensory processing, it is necessary to determine how thalamic inputs are integrated by their postsynaptic cortical neurons and propagated via intracolumnar and intercolumnar cortical pathways. This requires methods to identify discrete functional columns and to reveal the spatiotemporal propagation of thalamic inputs within and among these columns. In the present study we took advantage of a functional imaging approach (see Orbach and Cohen, 1983; Cinelli and Salzberg, 1987; Yuste et al., 1997; Keller et al., 1998) to investigate intracortical processing of thalamic inputs in the somatosensory cortex and its modulation by glutamatergic and GABAergic processes.

The somatosensory cortex of certain rodent species contains representations of the mystacial vibrissae (whiskers), which map

\footnotetext{
Received Sept. 29, 1999; revised Dec. 6, 1999; accepted Dec. 6, 1999.

This work was supported by US Public Health Service Grant NS-31078 (A.K.). We are grateful to Dr. Michael T. Shipley for valuable suggestions and support during the course of our studies and to Alison Thompson for outstanding technical expertise.

Correspondence should be addressed to Dr. Asaf Keller, Department of Anatomy and Neurobiology, University of Maryland School of Medicine, 685 West Baltimore Street, Baltimore, MD 21201. E-mail: akeller@umaryland.edu.

Copyright (C) 2000 Society for Neuroscience $0270-6474 / 00 / 201529-09 \$ 15.00 / 0$
}

in a one-to-one, topographic manner onto corresponding arrays of discrete cellular aggregates termed barrels (Woolsey and Van der Loos, 1970). Neurons in a layer IV barrel that corresponds to a particular whisker respond preferentially to stimulation of that whisker (for review, see Armstrong-James, 1995; Simons, 1995). Neurons in the supragranular and infragranular layers immediately above and below a barrel form a functional column of cells with similar response properties (for review, see Keller, 1995). In addition, individual barrels can be identified in unstained, in vitro brain slices (Agmon and Connors, 1991; Gottlieb and Keller, 1997). As a result, the barrel cortex is the only cortical region in which functional columns can be identified without the use of electrophysiological approaches, metabolic markers, or functional imaging. These advantages render the barrel cortex an excellent model for studying hierarchical processing of thalamic inputs by intracolumnar and intercolumnar synaptic interactions.

Some of these results appeared previously in abstract form (Laaris and Keller, 1999).

\section{MATERIALS AND METHODS}

Slice preparation. Animal protocols used in this study complied with all pertinent institutional and federal regulations. Young adult CD-1 male mice, 21-30 d old, were anesthetized with ketamine $(30 \mathrm{mg} / \mathrm{kg})$. The brains were removed, and $400-\mu \mathrm{m}$-thick thalamocortical slices were prepared as described by Agmon and Connors (1991). This preparation preserves both the ventrobasal (VB) nucleus of the thalamus and the somatosensory (barrel) cortex, including the functional connections between these structures. Slices were kept in a holding chamber that contained artificial CSF (ACSF) at room temperature, aerated with 95\% $\mathrm{O}_{2}$ and $5 \% \mathrm{CO}_{2}$. ACSF was composed of (in mM): $\mathrm{NaCl} 124, \mathrm{NaHCO}_{3}$ 26, $\mathrm{NaH}_{2} \mathrm{PO}_{4}$ 1.2, $\mathrm{KCl} 3.2, \mathrm{MgSO}_{4} 1.2, \mathrm{CaCl}_{2}$ 2.4, and glucose 10 .

One hour later, individual slices were stained with the voltage-sensitive dye RH-155 (100 $\mu \mathrm{M}$; Molecular Probes, Eugene, OR). The dye was dissolved in ACSF, and a single slice was placed in a static bath containing this solution, continuously arerated with $95 \% \mathrm{O}_{2}$ and $5 \% \mathrm{CO}_{2}$ for 30-60 min. The stained slice was then transferred to an immersion-type 
recording chamber and continuously perfused at $2 \mathrm{ml} / \mathrm{min}$ with ACSF at room temperature.

Electrical stimulation and recording. A bipolar stimulating electrode, insulated except at the tips, was placed in the VB thalamus to activate thalamocortical cells $(150-200 \mu \mathrm{sec})$. Constant current pulses were delivered through an optically isolated stimulus isolator (PSIU6; Grass, Quincy, MA) driven by a pulse generator (Grass S48). The pulse generator was also used to trigger image acquisition by the analog-to-digital (A/D) converter (see below). Glass pipettes (filled with $2 \mathrm{M} \mathrm{NaCl}, 2-5$ $\mathrm{M} \Omega$ ) were placed in layer IV to record thalamic-evoked field potentials. These recordings were digitized on-line, and stored on an Apple Macintosh computer.

Optical recordings. Methods used for recording voltage-sensitive optical signals are similar to those described in detail elsewhere (Salzberg et al., 1977; Wu and Cohen, 1993; Keller et al., 1998). To wash out unbound dye, stained slices were perfused with ACSF for at least 15 min before initiating the optical recording. The recording chamber was mounted on a fixed stage upright microscope (BX50WI; Olympus Optical, Tokyo, Japan) rigidly mounted on a vibration isolation table. A stabilized DC power source was used to power a $100 \mathrm{~W}$ tungsten-halogen lamp, and the light from this lamp was band-limited with interference and heat filters; unless otherwise indicated, a $720 \pm 40 \mathrm{~nm}$ bandpass interference filter was used (Omega Optical, Brattleboro, VT). Light transmitted through the preparation was collected through a $10 \times(0.3$ numerical aperture, Olympus) water-immersion objective, and projected onto a 464 element array of photodiodes (NeuroPlex; OptImaging, Fairfield, CT). Each photodiode sampled optical signals from a region of $\sim 60 \times 60 \mu \mathrm{m}^{2}$. The current output from each photodiode was separately converted to voltages and amplified in two separate stages $(1000 \times)$, multiplexed, and digitized at 12 bit resolution with an A/D converter. Optical signals were filtered at $500 \mathrm{~Hz}$ before digitizing. All electronic components are part of the commercial NeuroPlex system. Data were collected and stored on a personal computer controlled by NeuroPlex software (OptImaging).

To precisely identify the regions in the slice from which optical recordings were collected, a custom-designed beam-splitting device (Microscope Services, Rockville, MD) was used to simultaneously project the images of the slice and light from light-emitting diodes embedded in the photodiode array onto the image plane of a CCD camera (CCD72; Dage, Michigan City, IN). This allowed us to demarcate the locations of individual barrels and of laminar boundaries (Fig. 1). These anatomical features, observed in unstained slices, correlated well with their appearance in Nissl-stained sections.

Unless otherwise indicated, all recordings were obtained at a sample rate of $1.6 \mathrm{kHz}$. Optical responses depicted represent the average of five consecutive traces, collected at $20 \mathrm{sec}$ intervals. To correct for spatial differences in illumination intensity and light path length, the signal recorded from each detector was divided by the resting light intensity calculated for the corresponding detector. The resting light intensity for each detector was calculated by subtracting the intensity values recorded while the shutter was closed from those recorded while the shutter was open, when no stimulation was applied. The resulting signal amplitudes are expressed as a fractional change in absorption $(\Delta I / I)$. To quantify relative changes in light absorption, we calculated the mean and SD of the $\Delta I / I$ during the $100 \mathrm{msec}$ preceding the stimulus; poststimulus signal amplitudes are expressed as the number of SDs above these mean baseline values. Optical responses that are at least $2 \mathrm{SD}$ above this mean were considered significant.

Analyses of data were performed on an Apple Macintosh computer, using routines developed in Igor (WaveMetrics, Lake Oswego, OR). The unpaired Student's $t$ test was used for statistical analyses.

Pharmacological and ionic manipulations. Pharmacological agents were prepared immediately before use from stock solutions and dissolved in ACSF. The following agents were obtained from Research BiochemicalsSigma (Natick, MA): D(-)-2-amino-5-phosphonopentanoic acid (AP5), bicuculline methiodide (bicuculline), and tetrodotoxin (TTX). Nominally $\mathrm{Ca}^{2+}$-free solutions were prepared by replacing $\mathrm{Ca}^{2+}$ with equimolar concentrations of $\mathrm{Mg}^{2+}$; nominally $\mathrm{Mg}^{2+}$-free solutions were prepared by omitting $\mathrm{Mg}^{2+}$ from the solutions.

\section{RESULTS}

\section{Origin of optical signals}

In all experiments we stimulated the VB thalamus and recorded field potentials and voltage-sensitive dye signals from the barrel cortex. Field potentials recorded from layer IV show two compo-

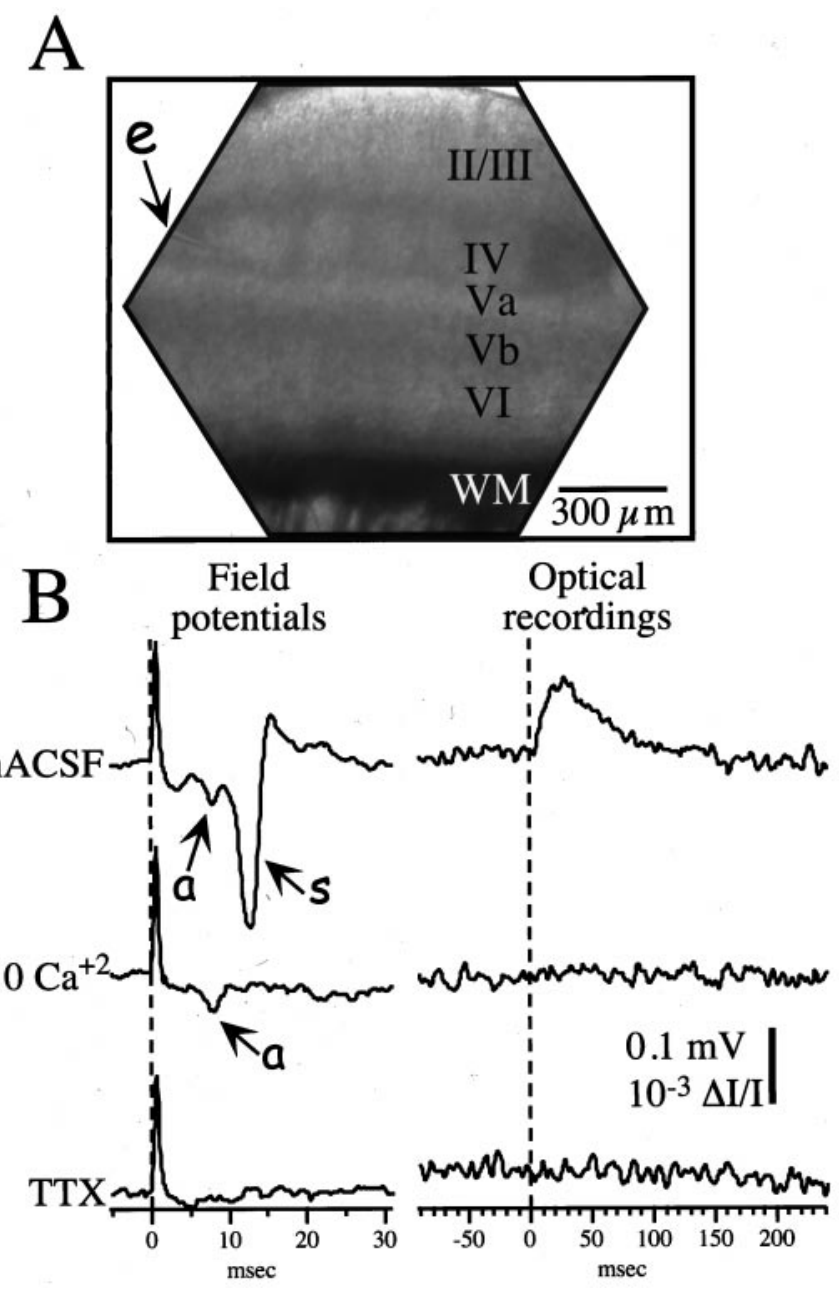

Figure 1. A, Videographic image of an in vitro slice through the barrel cortex, obtained during a recording session. The hexagon demarcates the border of the 464 element photodiode array. Cortical layers are indicated by roman numerals. Note the appearance of barrels in layer IV. A recording electrode $(e)$ is placed in a layer IV barrel to record field potentials. $B$, Simultaneous recordings of field potentials and voltagesensitive dye signals, in response to thalamic stimulation. In normal ACSF $(n A C S F)$ the field potential exhibits two components, and the optical response exhibits a single, depolarizing component. When synaptic transmission is suppressed in a nominally $\mathrm{Ca}^{2+}$-free solution $\left(0 \mathrm{Ca}^{2+}\right)$, the second component of the field potential $(s)$ and the optical response are abolished, suggesting that both represent postsynaptic activity of cortical neurons. The early component in the field potential $(a)$ is suppressed by the $\mathrm{Na}^{+}$channel antagonist TTX, suggesting that it represent the presynaptic thalamocortical compound action potential.

nents: an early-onset (3-5 msec) low-amplitude negative deflection, followed by one or more later and larger components (Fig. $1)$. The optical signals had a single component, with an onset latency of $5.27 \pm 1.54 \mathrm{msec}(n=84$ slices $)$ and a relatively slow rise time (measured from onset to peak; $21.61 \pm 5.56 \mathrm{msec} ; n=$ 84 ). To characterize the origin of the recorded signals, we pharmacologically isolated different components of the optically recorded and field potential responses. To suppress synaptic transmission, we bathed the slices in nominally $\mathrm{Ca}^{2+}$-free solutions. This resulted in complete suppression of the optical responses and of the later components of the evoked field potentials $(n=$ 11; Fig. 1). In contrast, the early component of the field potential was not affected, but it was completely abolished after application of the $\mathrm{Na}^{+}$channel antagonist TTX $(0.5 \mu \mathrm{M} ; n=4)$. 
These findings indicate that the optical responses and the late components of the field potentials are entirely dependent on synaptic transmission. This suggest that under our recording conditions, the optical responses represent postsynaptic responses in cortical neurons. Presynaptic, $\mathrm{Na}^{+}$-dependent thalamocortical compound action potentials, evident in the early component of the field potential recordings, are not detected optically. This may be attributable to the relatively low sampling frequency or the low numerical aperture objective we used.

In addition to dye-related signals, optical responses may also arise from sources intrinsic to the slice (Grinvald et al., 1988; Yuste et al., 1997). To determine whether such intrinsic signals contributed to the waveforms recorded in our study, we tested the dependence of these signals on the illumination wavelength. When the illumination was changed to a wavelength outside the absorption spectrum of the dye $(\geq 800 \mathrm{~nm})$, no optical signal was detected in the barrel cortex. This suggests that the optical signals represent dye-related responses and are not the result of intrinsic optical signals.

Dye-related optical signals may also originate from activation of glial cells. In this case, the optical responses recorded from glial cells are expected to exhibit a slow time course ( $>1 \mathrm{sec})$ compared with that of neuronal responses (Konnerth et al., 1987). However, optical signals recorded in the barrel cortex had only a single depolarizing component, whose duration was $99.92 \pm 21.34$ msec $(n=84$; Fig. 1$)$. These findings suggest that the dye-related optical signals analyzed in the present study reflect neuronal responses and are not related to signals originating from glial cells.

\section{Spatial distribution of optical signals}

To analyze the spatial propagation of the thalamic-evoked optical responses, we generated color-coded maps representing the instantaneous amplitude of the responses recorded by each photodiode (Fig. 2). In these maps, response amplitude is represented as the number of SDs above mean baseline values, calculated separately for each photodiode (see Materials and Methods).

VB-thalamus stimulus intensity was adjusted to levels $10 \%$ above the threshold for detecting an optical response. These stimulus levels ranged from 20 to $50 \mu \mathrm{A}$ and produced an identical pattern of response in all slices $(n=84)$. To identify the locus of these responses, we overlaid on the activity maps drawings of the laminar and barrel boundaries, obtained from videographic images and from Nissl-stained sections (see Materials and Methods; Fig. 2). This revealed that in all cases, low-intensity thalamic simulation evoked responses that were restricted to one or two barrel hollows, and the walls surrounding them, and to a region of similar size below those barrels, near the border between layers $\mathrm{Vb}$ and VI (Fig. 2A). The spatial spread of the response was identical throughout the duration of the response, and the optically recorded activity did not propagate beyond the regions activated initially. The activity patterns in Figure $2 A$ depict the maximal spatial propagation of the responses.

In most $(62 \%)$ of the slices the optical responses in layer IV and in the layer $\mathrm{Vb}-\mathrm{VI}$ border had identical onset latencies. Less frequently, responses appeared first in the layer $\mathrm{Vb}-\mathrm{VI}$ border $(21 \%)$, or in layer IV (17\%). In these cases, the difference in onset latency was 4-9 msec.

Increasing the stimulus intensity expanded the region from which optical responses were recorded, but these regions were still restricted to layer IV and the layer Vb-VI border (Figs. 1 $A$, 3). Even at stimulus intensities that were 10 times higher than the threshold levels (up to $500 \mu \mathrm{A}$ ), activity was restricted to the initially activated regions, and no further spatial propagation was observed $(n=9)$.

\section{NMDA receptors mediate spread of activity}

Intracortical synaptic interactions in the barrel cortex are dependent, in large part, on activation of glutamatergic NMDA receptors (Gil and Amitai, 1996b; Thomson and Deuchars, 1997; Huang et al., 1998). We therefore reasoned that activation of these receptors may augment intracortical synaptic interactions and enhance the spatial spread of activity in the barrel cortex. To test this hypothesis, we treated slices in a nominally magnesiumfree solution $\left(0 \mathrm{Mg}^{2+}\right)$, a condition that enhances the activation of NMDA receptors (Collingridge and Bliss, 1995).

In $0 \mathrm{Mg}^{2+}$, thalamic stimulation at intensities just above threshold resulted in dramatic alterations in the spatiotemporal activation patterns. As in control conditions, optical signals were recorded first from one or two barrels and the layer V-VI border immediately below them. However, activity then propagated vertically to the supragranular and infragranular layers and across the layer $\mathrm{Vb}-\mathrm{VI}$ border, with peaks of activity in these regions occurring 25-45 msec after stimulus (Figs. 2B,3). Activity then propagated to adjacent barrels and to the supragranular layers immediately above them (at 40-64 msec after stimulus) and finally to superficial layer II and to layer I (50-82 msec after stimulus). Similar spatiotemporal patterns were recorded from all slices tested in $0 \mathrm{Mg}^{2+}$ solutions $(n=17)$.

We estimated the intracortical propagation velocity of optical signals by measuring the delay between the onset of optical responses at two points in the slice and dividing this value by the distance between these points. The propagation of optical activity occurred at $0.112 \pm 0.028 \mathrm{~m} / \mathrm{sec}(n=17)$. Because our calculation omits the contribution of synaptic delays, and because we cannot determine the number of synaptic delays between the two points measured, this value may be lower than the actual conduction velocity of intracortical axons. Nevertheless, this value is similar to that calculated from measurements of the propagation of intracortical field potentials in the neocortex in vitro (Aroniadou and Keller, 1993) and from estimations of intracortical conduction velocities in the barrel cortex in vivo (Armstrong-James, 1995).

Relatively long-term incubation of cortical slices in solutions containing low concentrations of $\mathrm{Mg}^{2+}$ may evoke spontaneous epileptic activity (Tsau et al., 1998). In our preparation we did not observe paroxysmal activity in either the optical responses or the field potentials $(n=17)$. This may be because of the relatively short periods ( $\leq 15 \mathrm{~min}$ ) we applied nominally $\mathrm{Mg}^{2+}$-free solutions.

The enhanced propagation of activity was significantly $(p<$ $10^{-4}$ ) suppressed by applying the NMDA receptor antagonist AP5 (50 $\mu \mathrm{M} ; n=6$; Figs. 2C, 3). This finding supports the conclusion that activation of NMDA receptors is responsible for the enhanced spatiotemporal propagation of optical responses in $0 \mathrm{Mg}^{2+}$ conditions. Under these conditions, the voltagedependent $\mathrm{Mg}^{2+}$ block of the NMDA receptors is removed (Collingridge and Bliss, 1995), resulting in activation of intracortical synaptic interactions mediated by these receptors.

A similar enhancement of activity propagation in $0 \mathrm{Mg}^{2+}$ was recorded in response to stimulation of the internal capsule, in slices in which the connections between the VB thalamus and the barrel cortex were severed $(n=5)$. This suggests that activation of NMDA receptors within the barrel cortex is necessary to 

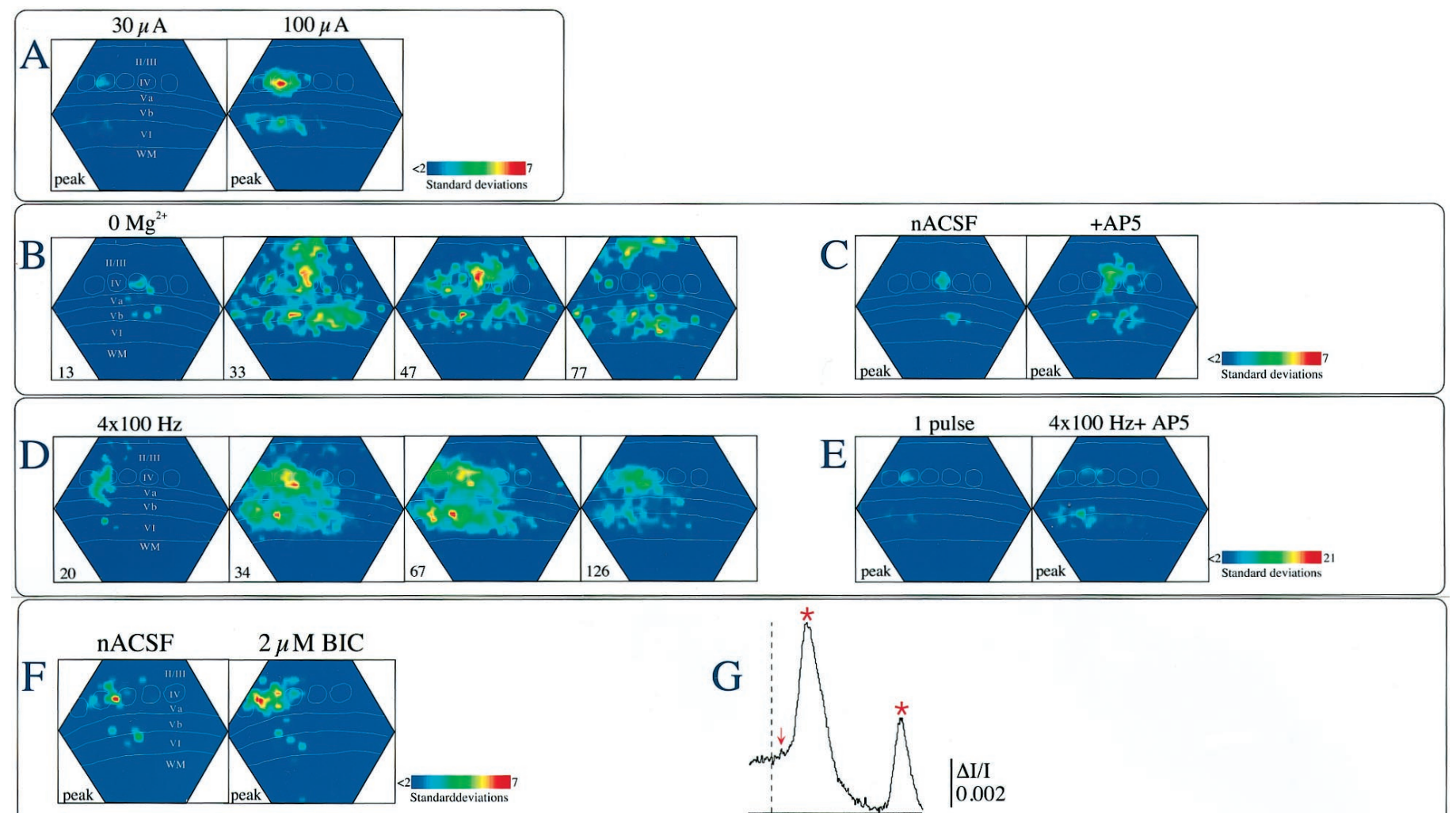

$5 \mu \mathrm{M} \mathrm{BIC}$

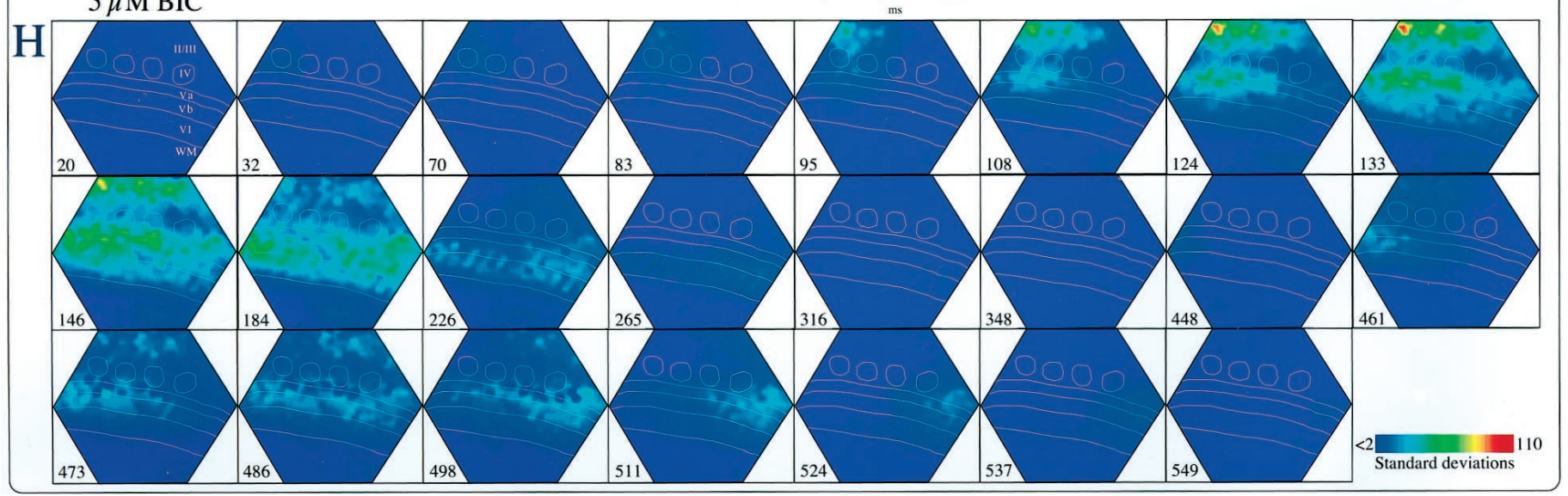

Figure 2. Propagation of optically recorded responses in the barrel cortex, in response to thalamic stimulation. Each panel depicts the amplitude of optical responses, recorded by each of the 464 photodiodes. Signal amplitudes, expressed as SDs above the mean baseline signals, are color-coded and interpolated. Time intervals (in milliseconds), indicated at the bottom left of each panel, are relative to the onset of stimulation. Panels in $A$, $C, E$, and $F$ depict signals recorded at the peak of the responses. Drawn on each panel are laminar and barrel hollow boundaries, identified in videographic images and from Nissl-stained sections. Laminae are indicated with roman numerals. A, Responses to low-intensity $(30 \mu \mathrm{A})$ and high-intensity (100 $\mu \mathrm{A})$ stimulation of the VB thalamus. In both conditions, responses are restricted to the layer IV barrels and the layer V-V I border. Data in these panels depict the maximal spatial propagation of the responses. $B$, Propagation of responses to thalamic stimulation $(20 \mu \mathrm{A})$ in nominally $\mathrm{Mg}^{2+}$-free ACSF. Activity propagates vertically within a barrel column and horizontally across the supragranular and infragranular layers. $C$, Responses recorded in the same slice depicted in $B$, in the presence of $1.2 \mathrm{mM} \mathrm{Mg}^{2+}(n A C S F)$ or in the presence of $0 \mathrm{Mg}^{2+}$ and the NMDA receptor antagonist AP5 $(+A P 5)$. The propagation of activity in $0 \mathrm{Mg}^{2+}$ conditions is significantly attenuated by AP5. $D$, Propagation of responses to a short train of thalamic stimuli $(4 \times 100 \mathrm{~Hz}$, $25 \mu \mathrm{A})$. Note the intracolumnar and intercolumnar propagation of activity. $E$, Activity recorded in the same slice depicted in $D$ in response to single-pulse stimulation of the thalamus $(25 \mu \mathrm{A}, 1 \mathrm{pulse})$ or in response to a train of stimuli, in the presence of the NMDA receptor antagonist AP5 (4X100 $H z+A P 5)$. The propagation of activity in response to repetitive stimulation is significantly attenuated by AP5. F, Responses to thalamic stimulation in nACSF or in the presence of the $\mathrm{GABA}_{\mathrm{A}}$ receptor antagonist bicuculline $(2 \mu \mathrm{MIC})$. Relatively low concentrations of bicuculline enhance the amplitude but not the spatial propagation of the responses. $G$, Optical activity to thalamic stimulation $($ at $t=0)$ recorded from a single photodiode, positioned in the supragranular layers, in the presence of $5 \mu \mathrm{M}$ bicuculline. The initial postsynaptic response (arrow) is followed by two successive paroxysmal events (asterisks). H, Propagation of activity in response to thalamic stimulation (single pulse, $20 \mu \mathrm{A}$ ), in the presence of $5 \mu \mathrm{M}$ bicuculline. The initial response in layer IV and the layer Vb-VI border $(t=20 \mathrm{msec})$ is followed by the initiation of a paroxysmal event in the same barrel $(t=32 \mathrm{msec})$. Activity first propagates vertically to the supragranular layers and then to the infragranular layers. The paroxysmal wave then propagates horizontally along separate bands in the supragranular and infragranular layers, mostly avoiding layer IV. Approximately 100 msec after the paroxysmal waved recede, a second paroxysmal wave appears in the infragranular layers, projects to the supragranular layers, and propagates horizontally along two separate bands. 


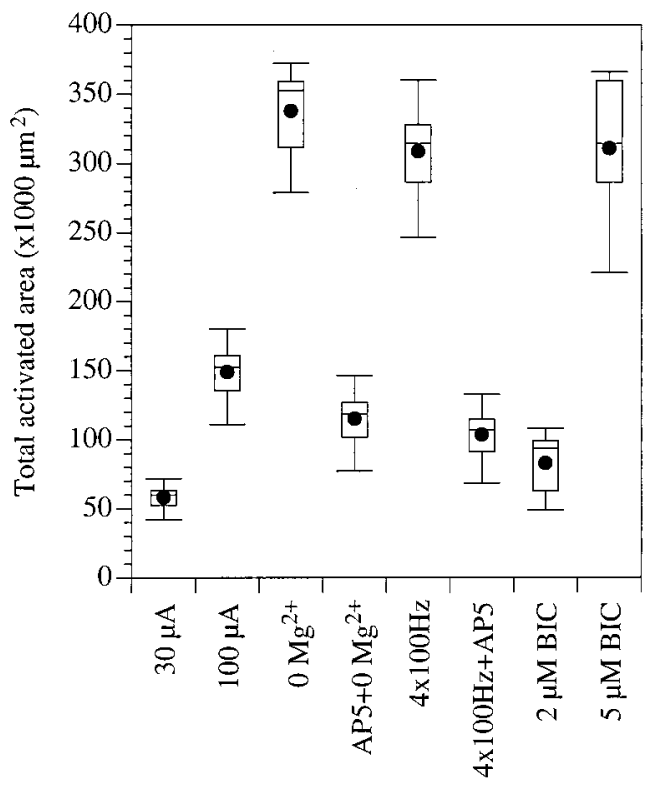

Figure 3. Box plots depicting the spatial propagation of activity after thalamic stimulation under different experimental conditions. Spatial propagation is expressed as the total surface area from which statistically significant optical responses were recorded.

enhance the propagation of activity, and that this effect does not require activation of NMDA receptors in the thalamus.

\section{Frequency-dependent modulation of signal propagation}

Under physiological conditions, voltage-dependent NMDA receptors can be activated by trains of stimuli (Collingridge and Bliss, 1995). We therefore tested whether a short train of lowintensity stimuli (four pulses, $30 \mu \mathrm{A}, 100 \mathrm{~Hz}$ ) would result in activation of NMDA receptors and enhanced intracortical propagation of activity. These stimulus parameters were chosen to mimic the trains of action potentials evoked in thalamocortical neurons in response to whisker deflections (Hartings and Simons, 1998; see Discussion).

In normal ACSF, a train of stimuli evoked spatiotemporal response patterns that were similar to those evoked in $0 \mathrm{Mg}^{2+}$ conditions (Figs. 2D, 3). Activity originated in one or two barrels and the layer $\mathrm{Vb}-\mathrm{VI}$ border immediately below them and propagated both vertically and horizontally to adjacent barrel columns. However, unlike the $0 \mathrm{Mg}^{2+}$ condition, high-frequency stimulation did not result in propagation of activity to the superficial part of layer II and to layer I (Fig. 2D). Furthermore, responses to high-frequency stimulation lasted significantly longer (105-222 msec), presumably reflecting temporal summation of the responses to the stimulus train. Similar spatiotemporal patterns were recorded in 16 slices in response to these stimulus parameters.

To determine whether the enhanced propagation was mediated by activation of NMDA receptors, we tested its sensitivity to the NMDA antagonist AP5 $(50 \mu \mathrm{M})$. In all cases $(n=9)$, AP5 significantly $\left(p<10^{-4}\right)$ attenuated the propagation of responses to high-frequency thalamic stimulation (Figs. $2 E, 3$ ). These findings suggest that stimulating the thalamus with a short pulse train activates synaptic interactions involving NMDA receptors and results in spread of activity mediated by intracortical connections.

Alternatively, high-frequency stimulation may have recruited additional thalamocortical neurons, and this enhanced afferent input may be responsible for the expanded cortical activity patters. If this were the case, increasing the stimulus intensity should produce a similar result. However, as described above (Fig. 2A), even at high stimulus intensities a single stimulus pulse failed to produce intracortical propagation of activity.

\section{GABAergic modulation of signal propagation}

$\mathrm{GABA}_{\mathrm{A}}$-receptor mediated inhibition profoundly affects the response properties of barrel cortex neurons (Brumberg et al., 1996; Kyriazi et al., 1996a,b, 1998). Many of these response properties are mediated, at least in part, by intracortical synaptic interactions (Armstrong-James, 1995; Keller, 1995). To determine the role of $\mathrm{GABA}_{\mathrm{A}}$ receptors in modulating these intracortical interactions, we compared cortical spatiotemporal activity patterns before and after applying the $\mathrm{GABA}_{\mathrm{A}}$ receptor antagonist bicuculline. Relatively low concentrations of bicuculline (1-2 $\mu \mathrm{M})$ resulted in an enhancement of the amplitude of the optical responses (by 50$80 \%, 63 \pm 12 \% ; n=14$ ) but did not affect the spatial propagation of activity (Fig. $2 F$ ). That is, as in control conditions, activity was restricted to one or two barrels in layer IV and to the layer $\mathrm{Vb}-\mathrm{VI}$ border immediately beneath them; the total area activated in the presence of bicuculline did not differ significantly from that activated under control conditions ( $p<10^{-4}$; Fig. 3).

Increasing the concentration of bicuculline to 5 or $10 \mu \mathrm{M}$ or incubating the slices in a low concentration of bicuculline for $>20$ min resulted in prominent thalamic-evoked paroxysmal (epileptic) events. These paroxysmal events are depicted in the optical recording, obtained from a single photodiode, in Figure $2 G$. Spatiotemporal analysis of the optical responses reveals the propagation patterns of these events (Fig. $2 H$ ). Similar patterns of thalamic-evoked paroxysmal activity patterns were recorded from all slices tested $(n=13)$. As in control conditions, there was an initial activation in a layer IV barrel and in layers $\mathrm{Vb}$ and VI below it (Fig. $2 H, G$, arrow). After a variable delay period (10-150 msec), a large-amplitude response originated from the activated barrel and propagated to the supragranular layers within the same barrel column, where it peaked 50-130 msec after stimulus. Activity then propagated vertically along the same column to the infragranular layers. Then, activity propagated horizontally across both the infragranular and supragranular layers at similar velocities. However, paroxysmal activity in the infragranular layers persisted longer than that in the supragranular layers (Fig. 2H).

In both the infragranular and supragranular layers, paroxysmal activity propagated at a velocity of $0.04 \pm 0.10 \mathrm{~m} / \mathrm{sec}(n=13)$, a value that is somewhat slower than that reported by Chervin et al. (1988) ( 0.06-0.09 m/sec). This discrepancy may be attributable to difference in recording temperature $\left(34^{\circ} \mathrm{C}\right.$ in the study by Chervin et al., 1988, vs room temperature in ours). Interestingly, relatively little activity was detected in the layer IV barrels, resulting in the appearance of two bands of propagating waves, one in the supragranular and the other in the infragranular layers (Fig. $2 H$ ).

In some slices ( $n=5$ of 13$)$, a second paroxysmal wave appeared 70-250 msec after the first wave subsided (Fig. 2G,H). In all cases, the second wave originated in the infragranular layers and propagated to the supragranular layers. Activity then propagated horizontally across both the supragranular and infragranular layers, with spatiotemporal characteristics similar to those of the initial paroxysmal waves.

Similar paroxysmal activity was recorded in response to stim- 
ulation of the internal capsule, in slices in which the connections between the VB thalamus and the barrel cortex were severed $(n=3)$. This suggests that, in agreement with previous studies (Connors, 1984; Chervin et al., 1988; Telfeian and Connors, 1998; Tsau et al., 1998), suppression of $\mathrm{GABA}_{\mathrm{A}}$ receptors within the barrel cortex is sufficient to evoke paroxysmal activity.

\section{DISCUSSION}

\section{Technical considerations}

The ability to identify individual functional columns in an unstained in vitro preparation allowed us to study the propagation of thalamic inputs via intracolumnar and intercolumnar cortical pathways. The functional imaging paradigm we used is advantageous in that it permits analyses, at a high resolution, of the spatiotemporal propagation of activity within the barrel cortex and the modulation of this activity by various manipulations. The optical signals recorded in our study are particularly sensitive to suprathreshold (i.e., spiking) activity in a synchronously activated population of neurons. This is because dye-related optical responses have a relatively low signal-to-noise ratio ( $\mathrm{Wu}$ and $\mathrm{Co}-$ hen, 1993). The sensitivity of our recordings is further limited by the use of relatively low-magnification objectives, which are necessary to simultaneously record activity from large regions in the slice. It is therefore possible that under our recording conditions, subthreshold responses, or suprathreshold responses of individual neurons, were not detected.

\section{Thalamic-evoked activity}

In response to low-intensity stimulation of the VB thalamus, activity was restricted to one or two barrels. This suggests that the stimulation activated neurons within a corresponding number of thalamic barreloids, because thalamocortical neurons within a single barreloid project preferentially to a single cortical barrel (Killackey and Leshin, 1975; Land et al., 1995; Keller and Carlson, 1999). Increasing the stimulus intensity resulted in simultaneous activation of additional barrels, presumably reflecting the recruitment of thalamocortical neurons in adjacent thalamic barreloids.

Responses recorded from layer IV barrels most likely represent postsynaptic activation on both excitatory and inhibitory barrel neurons, because both populations receive a relatively large number of thalamocortical synapses (Benshalom and White, 1986; White, 1986) and respond monosynaptically to thalamic stimulation (Swadlow et al., 1998; Gil et al., 1999; Katz et al., 1999). Optical responses in the barrels may also originate from the layer IV segments of dendrites belonging to cells whose parent somata are in other cortical layers, which are known to receive thalamocortical synapses (White, 1986). These may include layer V and VI pyramidal neurons, which are capable of producing $\mathrm{Na}^{+}$- and $\mathrm{Ca}^{2+}$-mediated dendritic spikes in response to synaptic inputs (Kim and Connors, 1993; Markram and Sakmann, 1994; Yuste et al., 1994; Schwindt and Crill, 1997).

In addition to responses in layer IV, thalamic stimulation also evoked optical signals near the layer Vb-VI border immediately below the activated barrels. These responses most likely originate from the somata of neurons that receive potent thalamic inputs, either from thalamocortical terminals in layer IV or from the smaller number of thalamic terminals in the infragranular layers (Keller et al., 1985; Chmielowska et al., 1989). These cells are likely to include corticothalamic cells, which receive a relatively high density of thalamic synapses on their apical dendrites in layer IV (White and Hersch, 1982; Keller and White, 1989). In most cases, responses in layer $\mathrm{Vb}-\mathrm{VI}$ occurred concurrently, or even before the responses in layer IV. This is in agreement with single-cell recording data demonstrating that neurons in the infragranular layers respond to whisker deflections concurrently with their counterparts in layer IV (Simons, 1978; Chapin, 1986; Swadlow, 1989; Armstrong-James et al., 1992).

This finding suggests that infragranular neurons are likely to be involved in early stages of processing whisker inputs. Indeed, because the axon collaterals of many infragranular neurons project to layer IV (Staiger et al., 1996; Gottlieb and Keller, 1997; Zhang and Deschênes, 1997), these cells may play a role in determining the properties of the layer IV cells-traditionally viewed as the initial sites of thalamocortical information processing. Thus, the classical view that thalamic inputs to the barrel cortex (and other cortical regions, e.g., Eccles, 1984) are first "processed" by layer IV cells, and that infragranular neurons, which project to subcortical targets, constitute the final "output" stage of cortical processing, may be oversimplified.

A potential complication is the possibility that thalamic stimulation also antidromically activated corticothalamic neurons and evoked responses in cortical neurons postsynaptic to the axon collaterals of these cells. This is unlikely because the stimulus threshold for activating thalamocortical (TC) axons is $\sim 1$ order of magnitude lower than the current required to antidromically activate corticothalamic (CT) cells (Ferster and Lindström, 1985; Stratford et al., 1996; Swadlow, 1998). In addition, previous studies reported that TC and $\mathrm{CT}$ axon bundles travel in different anteroposterior planes in the internal capsule, such that slices containing TC afferents rarely include CT axons (Agmon and Connors, 1991; Agmon and Connors, 1992). Finally, antidromic stimulation is expected to evoke optical signals in CT somata, and these signals should be resistant to suppression of synaptic transmission; however, all optical responses were suppressed by 0 $\mathrm{Ca}^{2+}$ conditions (Fig. 1).

\section{$\mathrm{GABA}_{\mathrm{A}}$ receptor-mediated responses}

Relatively low concentrations of the $\mathrm{GABA}_{\mathrm{A}}$ receptor antagonist bicuculline resulted in pronounced enhancement in the amplitude of thalamic-evoked responses but did not enhance the spatial spread of these responses. This finding suggests that GABAergic inhibition does not significantly affect the activation of intracolumnar or intercolumnar pathways in the barrel cortex.

Application of $\mathrm{GABA}_{\mathrm{A}}$ receptor antagonists in vivo results in an expansion of the surround receptive field size of layer IV barrel neurons, such that the responses of these cells to nonprincipal whiskers is dramatically enhanced (Brumberg et al., 1996; Kyriazi et al., 1996b). Our finding that low concentrations of bicuculline do not significantly affect intercolumnar synaptic interactions suggests that the receptive field expansions observed in vivo are related to modulation of synaptic interactions within individual barrels and are not dependent on changes in intercolumnar interactions. This lends further support to the hypothesis, formulated by Simons and collaborators (Simons and Carvell, 1989; Simons, 1995; Goldreich et al., 1999), that the response properties of layer IV barrel neurons are shaped primarily by inhibitory and excitatory synaptic interactions restricted to a single barrel.

In agreement with previous studies (Gil and Amitai, 1995; Telfeian and Connors, 1998), in the presence of higher concentrations of bicuculline thalamic stimulation resulted in paroxysmal or epileptic activity in the barrel cortex. The spatial spread of paroxysmal activity is thought to occur primarily through activation of intracortical excitatory synaptic pathways (Gutnick et al., 
1982; Traub and Wong, 1982; Chervin et al., 1988; Connors and Amitai, 1997). Therefore, analysis of this activity provides a useful tool for elucidating intracortical synaptic pathways (Fleidervish et al., 1998).

Thalamic-evoked paroxysmal activity was initiated in a layer IV barrel and propagated first to the supragranular layers immediately above that barrel. This is in agreement with reports on the initiation and vertical propagation of electrically recorded epileptic discharges in the neocortex (Connors, 1984). The anatomical substrates for the propagation to the supragranular layers are most likely the vertical axon collaterals of layer IV nonpyramidal neurons (Simons and Woolsey, 1984; Katz et al., 1999). The subsequent propagation of activity to the infragranular layers is likely mediated by descending axon collaterals belonging to supragranular pyramidal cells (Bernardo et al., 1990; Gottlieb and Keller, 1997; Katz et al., 1999). Horizontal, intracortical propagation of paroxysmal activity is mediated by intracortical synaptic interactions (Connors and Amitai, 1993), most likely involving axon collaterals of supragranular and infragranular pyramidal cells (Bernardo et al., 1990; Gottlieb and Keller, 1997). In agreement with previous studies, the velocity of this propagation was significantly slower than the conduction velocity of intracortical axons (Gutnick et al., 1982; Telfeian and Connors, 1998). This finding supports the hypothesis that epileptic activity propagates by synchronizing the activity of restricted cortical circuits (Traub and Wong, 1982).

Although large-amplitude paroxysmal activity propagated across the supragranular and infragranular layers, these propagating waves largely avoided the layer IV barrels (Fig. $2 H$ ). This finding is in agreement with data suggesting that there are relatively few direct connections between the hollows of neighboring barrels (Simons and Woolsey, 1984; Goldreich et al., 1999; Katz et al., 1999; Kim and Ebner, 1999). This finding is also in agreement with data demonstrating that although paroxysmal activity may be initiated in layer IV (Connors, 1984), it can propagate horizontally across the supragranular or infragranular layers, even when these layers are surgically isolated from layer IV (Telfeian and Connors, 1998).

\section{NMDA receptor-mediated responses}

In contrast to the limited effects of low concentrations of bicuculline, activation of NMDA receptors resulted in dramatic propagation of thalamic-evoked activity throughout the barrel cortex. These findings suggest that NMDA receptors are critically involved in intracortical synaptic interactions in the barrel cortex, in agreement with previous in vitro data (Thomson et al., 1988; Gil and Amitai, 1996a). Indeed, our findings suggest that suprathreshold intracortical propagation of thalamic-evoked activity requires activation of NMDA receptors. This is in agreement with in vivo findings that suprathreshold, intercolumnar synaptic interactions, at least in the supragranular layers of the barrel cortex, are entirely dependent on activation of NMDA receptors (Huang et al., 1998), and that the response properties of neurons in the somatosensory cortex are profoundly influenced by manipulating NMDA receptors (Armstrong-James et al., 1993; Whitsel et al., 1999).

We have not yet identified the neurons responsible for mediating the suprathreshold, NMDA receptor-dependent activity propagation. Although thalamocortical synapses activate both NMDA and non-NMDA receptors (Gil and Amitai, 1996a), the large efficacy of these synapses (Gil et al., 1999) suggests that they are not likely to be enhanced further by unmasking of NMDA receptors. In contrast, the significantly smaller efficacy of intracortical synaptic interactions (Gil et al., 1999) renders them particularly sensitive to such an enhancement. Indeed, our findings suggest that NMDA receptor-dependent activity propagates via intracortical connections from thalamic-recipient neurons in layers IV and the V-VI border to their postsynaptic targets in the same and adjacent barrel columns.

\section{Responses to repetitive stimulation}

In addition to their role in synaptic development and plasticity, NMDA receptors have an important role as coincidence detectors (Collingridge and Singer, 1990; Markram et al., 1997). That is, the voltage-dependence of these receptors renders them particularly sensitive to synaptic inputs that occur when the postsynaptic cell is depolarized, for example, by earlier inputs in a repetitive train. Here we report that repetitive stimulation of thalamocortical afferents results in enhanced propagation of activity in the barrel cortex, by activation of NMDA receptordependent intracortical pathways.

During tactile discrimination, rats whisk at frequencies ranging from 1 to $20 \mathrm{~Hz}$, with a dominant frequency at $\sim 8 \mathrm{~Hz}$ (Carvell and Simons, 1990; Kleinfeld et al., 1999). Thalamocortical neurons can be entrained by whisker deflections of at least $12 \mathrm{~Hz}$ (Hartings and Simons, 1998), and respond to single whisker deflections with, on average, two spikes at $\sim 350 \mathrm{~Hz}$ (Kyriazi et al., 1994). The stimulus parameters tested in the present study (four pulses at $100 \mathrm{~Hz}$ ) are therefore well within the physiological parameters that are likely to occur during exploratory whisking.

Nearly all in vivo studies of the barrel cortex tested the receptive field properties of barrel cortex neurons in response to single whisker deflections. Our findings suggest that during highfrequency exploratory whisking, the responses of these neurons would be dramatically different. Specifically, because of the frequency-dependent activation of NMDA receptor-mediated intracortical connections, the responses of barrel cortex neurons to nonprincipal whiskers (the surround receptive field) would be significantly larger than those recorded in response to single whisker deflections.

\section{REFERENCES}

Agmon A, Connors BW (1991) Thalamocortical responses of mouse somatosensory (barrel) cortex in vitro. Neuroscience 41:365-379.

Agmon A, Connors BW (1992) Correlation between intrinsic firing patterns and thalamocortical synaptic responses of neurons in mouse barrel cortex. J Neurosci 12:319-329.

Armstrong-James M (1995) The nature and plasticity of sensory processing within adult rat barrel cortex. In: Cerebral cortex, Vol 11, The barrel cortex of rodents (Jones EG, Diamond IT, eds), pp 333-373. New York: Plenum.

Armstrong-James M, Fox K, Dasgupta A (1992) Flow of excitation within rat barrel cortex on striking a single vibrissa. J Neurophysiol 68:1345-1358.

Armstrong-James M, Welker E, Callahan CA (1993) The contribution of NMDA and non-NMDA receptors to fast and slow transmission of sensory information in the rat $\mathrm{Sl}$ barrel cortex. $\mathrm{J}$ Neurosci 13:2149-2160.

Aroniadou VA, Keller A (1993) The patterns and synaptic properties of horizontal intracortical connections in the rat motor cortex. J Neurophysiol 70:1493-1553.

Benshalom G, White EL (1986) Quantification of thalamocortical synapses with spiny stellate neurons in layer IV of mouse somatosensory cortex. J Comp Neurol 253:303-314.

Bernardo KL, McCasland JS, Woolsey TA, Strominger RN (1990) Local intra- and interlaminar connections in mouse barrel cortex. J Comp Neurol 291:231-255.

Brumberg JC, Pinto DJ, Simons DJ (1996) Spatial gradients and inhibitory summation in the rat whisker barrel system. J Neurophysiol $76: 130-140$.

Carvell G, Simons DJ (1990) Biometric analyses of vibrissal tactile discrimination in the rat. J Neurosci 10:2638-2648. 
Chapin JK (1986) Laminar differences in sizes, shapes, and response profiles of cutaneous receptive fields in the rat SI cortex. Exp Brain Res 62:549-559.

Chervin RD, Pierce PA, Connors BW (1988) Periodicity and directionality in the propagation of epileptiform discharges across neocortex. J Neurophysiol 60:1695-1713.

Chmielowska J, Carvell GE, Simons DJ (1989) Spatial organization of thalamocortical and corticothalamic projection systems in the rat SmI barrel cortex. J Comp Neuruol 285:325-338.

Cinelli AR, Salzberg BM (1987) Optical recording of electrical activity in slices of mammalian olfactory structures: extrinsic signals from olfactory bulb and pyriform and sulcal cortices of the mouse. Soc Neurosci Abstr 13:1411.

Collingridge GL, Bliss TVP (1995) Memories of NMDA receptors and LTP. Trends Neurosci 18:54-56.

Collingridge GL, Singer W (1990) Excitatory amino acid receptors and synaptic plasticity. Trends Pharmacol Sci 11:290-296.

Connors BW (1984) Initiation of synchronized neuronal bursting in neocortex. Nature 310:685-687.

Connors BW, Amitai Y (1993) Generation of epileptiform discharge by local circuits of neocortex. In: Epilepsy: models, mechanisms and concepts (Schwartzkroin P, ed), pp 388-423. New York: Oxford UP.

Connors BW, Amitai Y (1997) Making waves in the neocortex. Neuron 18:347-349.

Eccles JC (1984) The cerebral neocortex: a theory of its operation. In: Cerebral cortex, Vol 2, Functional properties of cortical cells (Jones EG, Peters A, eds), pp 1-36. New York: Plenum.

Felleman DJ, Van Essen DC (1991) Distributed hierarchical processing in the primate cerebral cortex. Cereb Cortex 1:1-47.

Ferster D, Lindström S (1985) Synaptic excitation of neurones in area 17 of the cat by intracortical axon collaterals of cortico-geniculate cells. J Physiol (Lond) 367:233-252.

Fleidervish IA, Binshtok AM, Gutnick MJ (1998) Functionally distinct NMDA receptors mediate horizontal connectivity within layer 4 of mouse barrel cortex. Neuron 21:1055-1065.

Gil Z, Amitai Y (1995) Cortical synchronized activity evoked by thalamocortical stimulation in vitro. Neurosci Lett 183:13-16.

Gil Z, Amitai Y (1996a) Adult thalamocortical transmission involves both NMDA and non-NMDA receptors. J Neurophysiol 76:2547-2554.

Gil Z, Amitai Y (1996b) Properties of convergent thalamocortical and intracortical synaptic potentials in single neurons of neocortex. J Neurosci 16:6567-6578.

Gil Z, Connors BW, Amitai Y (1999) Efficacy of thalamocortical and intracortical synaptic connections: quanta, innervation, and reliability. Neuron 23:385-397.

Gilbert CD (1992) Horizontal integration and cortical dynamics. Neuron 9:1-13.

Goldreich D, Kyriazi HT, Simons D (1999) Functional independance of layer IV barrels in rodent somatosensory cortex. J Neurophysiol 82:1311-1316.

Gottlieb JP, Keller A (1997) Intrinsic circuitry and physiological properties of pyramidal neurons in rat barrel cortex. Exp Brain Res 115:47-60.

Grinvald A, Frostig RD, Lieke E, Hildesheim R (1988) Optical imaging of neuronal activity. Physiol Rev 68:1285-1366.

Gutnick MJ, Connors BW, Prince DA (1982) Mechanisms of neocortical epileptogenesis in vitro. J Neurophysiol 48:1321-1335.

Hartings JA, Simons DJ (1998) Thalamic relay of afferent responses to 1 - to $12-\mathrm{Hz}$ whisker stimulation in the rat. $\mathrm{J}$ Neurophysiol 80:1016-1019.

Huang W, Armstrong-James M, Rema V, Diamond ME, Ebner FF (1998) Contribution of supragranular layers to sensory processing and plasticity in adult barrel cortex. J Neurophysiol 80:3261-3271.

Iwamura Y (1993) Dynamic and hierarchical processing in the monkey somatosensory cortex. Biomed Res 14:107-111.

Katz L, Li Y, Keller A (1999) Morphological and biophysical properties of identified neurons in mouse barrel cortex. Soc Neurosci Abstr 25:275.210.

Keller A (1995) Synaptic organization of the barrel cortex. In: Cerebral cortex, Vol 11, The barrel cortex of rodents (Jones EG, Diamond IT, eds), pp 221-262. New York: Plenum.

Keller A, Carlson GC (1999) Neonatal whisker clipping alters intracortical, but not thalamocortical projections in rat barrel cortex. J Comp Neurol 412:83-94.
Keller A, White EL (1989) Triads: a synaptic network component in the cerebral cortex. Brain Res 496:105-112.

Keller A, White EL, Cipolloni PB (1985) The identification of thalamocortical axon terminals in barrels of mouse SmI cortex using immunohistochemistry of anterogradely transported lectin (Phaseolus vulgaris lecoagglutinin). Brain Res 343:159-165.

Keller A, Yagodin S, Aroniadou-Anderjaska V, Zimmer LA, Ennis M, Sheppard NF, Shipley MT (1998) Synaptic physiology of rat olfactory bulb glomeruli revealed by optical imaging. J Neurosci 18:2602-2612.

Killackey HP, Leshin S (1975) The organization of specific thalamocortical projections to the posteromedial barrel subfield of the rat somatic sensory cortex. Brain Res 86:469-472.

Kim HG, Connors BW (1993) Apical dendrites of the neocortex: correlation between sodium- and calcium-dependent spiking and pyramidal cell morphology. J Neurosci 13:5301-5311.

Kim U, Ebner FF (1999) Barrels and septa: separate circuits in rat barrel field cortex. J Comp Neurol 408:489-505.

Kleinfeld D, Berg RW, O'Conner SM (1999) Anatomical loops and their electrical dynamics in relation to whisking by rat. Somatosens Motor Res 16:69-88.

Konnerth A, Obaid AL, Salzberg DM (1987) Optical recording of electrical activity from parallel fibers and other cell types in skate cerebellar slices in vitro. J Physiol (Lond) 393:681-702.

Kyriazi HT, Carvell GE, Simons DJ (1994) OFF response transformations in the whisker/barrel system. J Neurophysiol 72:392-401.

Kyriazi HT, Carvell GE, Brumberg JC, Simons DJ (1996a) Effects of baclofen and phaclofen on receptive field properties of rat whisker barrel neurons. Brain Res 712:325-328.

Kyriazi HT, Carvell GE, Brumberg JC, Simons DJ (1996b) Quantitative effects of GABA and bicuculline methiodide on receptive field properties of neurons in real and simulated barrels. J Neurophysiol 75:547-560.

Kyriazi H, Carvell GE, Brumberg JC, Simons DJ (1998) Laminar differences in bicuculline methiodide's effects on cortical neurons in the rat whisker barrel system. Somatosens Motor Res 15:146-156.

Laaris N, Keller A (1999) Frequency-dependent regulation of synaptic interactions in the barrel cortex. Soc Neurosci Abstr 25:275.11.

Land PW, Buffer SA, Yaskosky JD (1995) Barreloids in adult rat thalamus: three-dimensional architecture and relationship to somatosensory cortical barrels. J Comp Neurol 355:573-588.

Markram H, Sakmann B (1994) Calcium transients in dendrites of neocortical neurons evoked by single subthreshold excitatory postsynaptic potentials via low-voltage-activated calcium channels. Proc Natl Acad Sci USA 91:5207-5211.

Markram H, Lübke J, Frotscher M, Sakmann B (1997) Regulation of synaptic efficacy by coincidence of postsynaptic APs and EPSPs. Science 275:213-215.

Orbach HS, Cohen LB (1983) Optical monitoring of activity from many areas of the in vitro and in vivo salamander olfactory bulb: a new method for studying functional organization in the vertebrate central nervous system. J Neurosci 3:2251-2262.

Rauschecker JP, Tian B, Pons T, Mishkin M (1997) Serial and parallel processing in rhesus monkey auditory cortex. J Comp Neurol 382:89-103.

Salzberg BM, Grinvald A, Cohen LB, Davila HV, Ross WN (1977) Optical recordings of neuronal activity in an invertebrate central nervous system: simultaneous monitoring of several neurons. J Neurophysiol 40:1281-1291.

Schwindt PC, Crill WE (1997) Local and propagated dendritic action potentials evoked by glutamate iontophoresis on rat neocortical pyramidal neurons. J Neurophysiol 77:2466-2483.

Simons DJ (1978) Response properties of vibrissa units in rat SI somatosensory neocortex. J Neurophysiol 41:798-820.

Simons DJ (1995) Neuronal integration in the somatosensory whisker/ barrel cortex. In: Cerebral cortex, Vol 11, The barrel cortex of rodents (Jones EG, Diamond IT, eds), pp 263-297. New York: Plenum.

Simons DJ, Carvell GE (1989) Thalamocortical response transformation in rat vibrissa/barrel system. J Neurophysiol 61:311-330.

Simons DJ, Woolsey TA (1984) Morphology of Golgi-Cox-impregnated barrel neurons in rat SmI cortex. J Comp Neurol 230:119-132.

Staiger JF, Zilles K, Freund TF (1996) Recurrent axon collaterals of corticothalamic projection neurons in rat primary somatosensory cortex contribute to excitatory and inhibitory feedback-loops. Anat Embryol 194:533-543. 
Stone J, Dreher B, Leventhal A (1979) Hierarchical and parallel mechanisms in the organization of visual cortex. Brain Res Rev 1:345-394.

Stratford KJ, Tarczy-Hornoch K, Sprengel R (1996) Excitatory inputs to spiny stellate cells in cat visual cortex. Nature 382:258-261.

Swadlow HA (1989) Efferent neurons and suspected interneurons in S-1 vibrissa cortex of the awake rabbit-receptive fields and axonal properties. J Neurphysiol 62:288-308.

Swadlow HA (1998) Neocortical efferent neurons with very slowly conducting axons: strategies for reliable antidromic identification. J Neurosci Methods 79:131-141.

Swadlow HA, Beloozerova IN, Sirota MG (1998) Sharp, local synchrony among putative feed-forward inhibitory interneurons of rabbit somatosensory cortex. J Neurophysiol 79:567-582.

Telfeian AE, Connors BW (1998) Layer-specific pathways for the horizontal propagation of epileptiform discharges in neocortex. Epilepsia 39:700-708.

Thomson AM, Deuchars J (1997) Synaptic interactions in neocortical local circuits: Dual intracellular recordings in vitro. Cereb Cortex 7:510-522.

Thomson AM, Girdlestone D, West DC (1988) Voltage-dependent currents prolong single-axon postsynaptic potentials in layer III pyramidal neurons in rat cortical slices. J Neurophysiol 60:1896-1907.

Traub RD, Wong RK (1982) Cellular mechanisms of neuronal synchronization in epilepsy. Science 239:1147-1150.

Tsau Y, Guan L, Wu JY (1998) Initiation of spontaneous epileptiform activity in the neocortical slice. J Neurophysiol 80:978-982.
White EL (1986) Termination of thalamic affrents in the cerebral cortex. In: Cerebral cortex, Vol 5, Sensory-motor areas and aspects of cortical connectivity (Jones EG, Peters A, eds), pp 271-289. New York: Plenum.

White EL, Hersch SM (1982) A quantitative study of thalamocortical and other synapses involving the apical dendrites of corticothalamic projection cells in mouse SmI cortex. J Neurocytol 11:137-157.

Whitsel BL, Favorov O, Delemos KA, Lee C-J, Tommerdahl M, Essick GK, Nakhle B (1999) SI neuron response variability is stimulus tuned and NMDA receptor dependent. J Neurophysiol 81:2988-3006.

Woolsey TA, Van der Loos H (1970) The structural organization of layer IV in the somatosensory region (SI) of mouse cerebral cortex. Brain Res 17:205-242.

Wu J-Y, Cohen LB (1993) Fast multisite optical measurement of membrane potential. In: Fluorescent and luminescent probes for biological activity (Mason WT, ed), pp 389-404. London: Academic.

Yuste R, Gutnick MJ, Saar D, Delaney KR, Tank DW (1994) $\mathrm{Ca}^{2+}$ accumulations in dendrites of neocortical pyramidal neurons: an apical band and evidence for two functional compartments. Neuron 13:23-43.

Yuste R, Tank DW, Kleinfeld D (1997) Functional study of the rat cortical microcircuitry with voltage-sensitive dye imaging of neocortical slices. Cereb Cortex 7:546-558.

Zhang ZW, Deschênes M (1997) Intracortical axonal projections of lamina VI cells of the primary somatosensory cortex in the rat: a single-cell labeling study. J Neurosci 17:6365-6379. 